\title{
Methicillin-Resistant Staphylococcus aureus Infections in Uppsala County, Sweden
}

\author{
Brith Christenson ${ }^{1}$, Bodil Ardung ${ }^{1}$ and Staffan Sylvan ${ }^{* 1,2}$ \\ ${ }^{I}$ The Department of Communicable Diseases Control and Prevention, Uppsala County Council, ${ }^{2}$ Department of Medical \\ Sciences, Uppsala University Hospital, Sweden
}

\begin{abstract}
The epidemiology of community-acquired (CA) and health care-associated (HCA) Methicillin-resistant Staphylococcus aureus (MRSA) infections were investigated in a prospective 3-year (2004-2006) surveillance study in Uppsala County. MRSA was isolated from all patients with soft tissue lesions attending hospitals and primary care clinics, as well as by systematic screening, regardless of symptoms, from all patients seeking medical care who had been treated abroad. Pulsed-field gel electrophoresis (PFGE), multilocus sequence typing (MLST) and spa typing were performed. The Panton-Valentine leukocidin (PVL) gene and resistance profiles were recognised. The cost of bacterial analysis was calculated. During the surveillance period, isolates were collected from 7967 individuals of whom 82 were colonised or infected with MRSA.

(24 HCA and $58 \mathrm{CA}$ ). A majority (65\%) of the MRSA isolates originating outside Sweden. The isolates could be assigned into nine well-known international clones. The most frequent clone was CC8 (32\%) within four clusters were identified and equally distributed between HCA and CA-isolates. The next most frequent clone was CC80 (DK E97-1) (23\%) only discovered in CA isolates. Resistance to antibiotics other than $\beta$-lactams was found in $25 \%$ of the domestic isolates and in $60 \%$ of isolates originating abroad. None of the HCA isolates carried the virulence determinant PVL gene. There was no spread of MRSA in the community or in hospitals during the surveillance period. Most domestic cases had certain risk factors. Travellers from or family relatives in the Middle East or Asia were highly overrepresented. To save costs selected screening is recommended.
\end{abstract}

Keywords: HCA-MRSA, CA-MRSA, PFGE, MLST, clonal complexes.

\section{INTRODUCTION}

Staphylococcus aureus is a causal agent of the nose and throat that rarely brings about infections, but it is also a leading cause of bacterial infections responsible for a wide variety of diseases and is known for life-threatening infections, including septicaemia, pneumonia and endocarditis. Two groups of Methicillin-resistant strains of Staphylococcus aureus (MRSA) are known: hospital-or health care-associated (HCA-MRSA) and communityassociated (CA-MRSA) infections [1, 2].

HCA-MRSA infections have global distribution and are the leading cause of nosocomial infections. These infections mainly occur in individuals with risk factors (e.g., in those that are immune compromised and with abscesses or wound lesions) or in connection with surgery. A high level of multidrug resistant MRSA has been reported, which emphasises the importance of infection control measures with molecular typing in conjunction with effective and restricted antimicrobial prescription.

An increase in MRSA infections seems to have occurred in several countries, but there have also been reports of decreasing prevalence in other countries. Because of the implementation of effective long-term control measures against infection a decrease of MRSA has been reported in

Address correspondence to this author at Smittskyddsenheten, Gränby Bilgata 2, SE 75185 Uppsala, Sweden; Tel: +46-18-6119220; Fax: +46-18552901; E-mail: staffan.sylvan@lul.se
France and Slovenia demonstrating that control of the spread of MRSA is achievable [2]. However, there are reports from the UK that more than $40 \%$ of S. aureus from bloodstream infections were MRSA. What is even more alarming are the high figures reported in Japan and the USA [3].

A change in the epidemiology of MRSA has recently been discovered in terms of an increase and dissemination of MRSA in the community, especially in the USA. MRSA infections are no longer confined to healthcare institutions, and MRSA strains are found in yet more genetic lineages. CA-MRSA has become epidemic, spreading worldwide $[4,5]$.

The prevalence of CA-MRSA infections appears to be lower in Europe than in the USA though recent reports indicate that the prevalence is increasing in certain European countries [2]. CA-MRSA infections tend to affect healthy individuals. However, fatal cases of CA-MRSA infections in children without identified risk have been reported [6]. CA-MRSA is genetically different from HCA-MRSA, expressing different virulence factors but is also sharing common attributes with HCA-MRSA [7]. CA-MRSA often expresses the toxin PantonValentine leukocidin (PVL) gene and is generally not multidrug resistant [3]. The PVL gene has been linked to increased disease severity but its role in disease severity is not fully understood [8]. Necrotising fasciitis that is caused by CA-associated MRSA has been reported in patients with co-existing conditions or risk factors [9]. Pulsed-field gel electrophoresis (PFGE) is the most commonly used method to study the epidemiology and dissemination of MRSA. However, for inter-laboratory 
comparability, multilocus sequence typing (MLST) is the most frequently used method for identifying different clones circulating within populations in diverse geographic areas. Epidemiological studies have indicated that few pandemic clones are responsible for the majority of the MRSA infections and that there are five hospital-acquired clonal complexes (CCs) that are internationally dominating $(\mathrm{CC} 5, \mathrm{CC} 8, \mathrm{CC} 22, \mathrm{CC} 30$ and $\mathrm{CC} 45)$ and within each clonal complex prevalent clones have been genetically characterised $[10,11]$. It has been proposed that successful MRSA clones might have acquired virulence factors in order to compensate for the loss of associated resistance factors [12]. Different CA-MRSA clones are circulating in Europe, whereas in USA one clone, USA300 (ST8) predominates [13]. This USA300 clone, related to the Iberian clone $\mathrm{CC} 8$, is increasing in a number of countries. Some of these CA-MRSA strains have been found infiltrating hospitals and replacing other MRSA strains [13].

There are many different strains in the CC8 and these are commonly referred to as the Iberian clone, the Lyon Archaic clone, the Brazilian Hungarian clone, the USA300 etc.

In Europe, the European CA-MRSA clone CC80 (sequence type 80 ) has often caused community-associated MRSA infections. One characteristic of CC80 isolates that differs from other CA strains is their resistance to fusidic acid. The increase of CA MRSA isolates (DK E97-1) observed recently in Denmark belonged to this clone [14]. In Sweden, CC80 is one of the most common clones [15].

Although Sweden is regarded as a low-prevalence country of MRSA there have been reports of an increasing number of MRSA infections.

The purpose of this prospective epidemiological study was to recognise the spread and risk factors of HCA-MRSA and CA-MRSA infections combined with cluster analysis. The aims, relevant to this study, included to evaluate the purposeful use of screenings activities and calculate the cost of bacterial analysis per identified patient.

\section{MATERIALS AND METHODS}

\section{Sampled Population}

This prospective surveillance study of CA-MRSA and HCA-MRSA isolates was conducted from 2004-2006 in Uppsala County (population approximately $330 \quad 000$ inhabitans), a region close to the Stockholm urban area. MRSA was isolated from all patients seeking medical care with skin and soft tissue lesions, abscesses, wounds, urinary tract infection, blood, bone/joint, etc. Moreover, systematic screening for MRSA carriage was performed, regardless of symptoms, in all patients who were seeking medical care and had been treated in hospitals outside Sweden during the last year or in the Stockholm area where an outbreak of MRSA occurred in 2002. In line with the Swedish Communicable Diseases Act contact tracing of relatives and household members to persons with MRSA infection was performed. These concerned all cases both foreign born and domestic cases. Due to Swedish low all carriers found by contact tracing are reported and notified. Patients and personnel were screened at hospital wards and in geriatric long -term facilities when a case of MRSA infection was discovered. Clinical and epidemiological information was obtained to determine risk factors and other characteristics associated with MRSA infection.

\section{Isolates}

During the surveillance study, samples from 7967 patients attending 2 hospitals, 35 primary care clinics and 2 out-patients settings were obtained (Table 1). Totally, 82 MRSA infections were identified from 2004-2006 (24 HCA infections obtained from 5787 patients and 58 CA infections from 2180 patients). All isolates were subjected to PFGH analysis in accordance with the Harmony protocol [16]. Staphylococcus protein A gene (spa) typing, a DNA sequence-based method for molecular analysis, was done as previously described [17]. MLST was performed on 79\% of the isolates to determine the prevalence and epidemiology of major MRSA clones [18]. The virulence determinant the PVL-encoding gene was detected [19]. The majority of the MRSA isolates were tested against other antibiotics than $\beta$ lactams.

\section{Classification}

The predominant consensus is that the CA-MRSA isolate is distinguished from the HA-MRSA isolate if the colonisation or infection are made in the outpatient settings or by a culture positive MRSA infection within $48 \mathrm{~h}$ of hospitalisation in a patient with no prior history of MRSA infection or colonisation, as well as no history of infection exposure in a health care facility in the past year. The present classification was based on these criteria. To our knowledge, individuals classified as CA-MRSA had no close hospitalisation. The distinction between carriers and infection was based on the notion that carriers were screened without symptoms, wounds or skin tissue lesions or because of contact tracing in connection to a MRSA case. Based on these data, patients were categorised into four groups, irrespective of whether they were infected or carriers. Contacts were categorised in the same group as the index case: (i) CA-MRSA infection originating in Sweden (Table 2), (ii) HCA-MRSA infection originating in Sweden (Table

Table 1. Distribution and Costs of MRSA Isolates During 3-Year Surveillance (2004 - 2006)

\begin{tabular}{|c|c|c|c|c|c|c|c|c|}
\hline Unit Providing Tests & $\begin{array}{c}\text { Samples } \\
\text { No. }\end{array}$ & $\begin{array}{c}\text { Domestic } \\
\text { No. }\end{array}$ & $\begin{array}{c}\text { Abroad } \\
\text { No. }\end{array}$ & $\begin{array}{c}\text { Total } \\
\text { No. }\end{array}$ & \multicolumn{2}{|c|}{ Costs } & \multicolumn{2}{|c|}{ Costs/Identified Per Patient } \\
\hline Hospitals & 12838 & 22 & 17 & 24 & 5.2 million & (742 900) & 216700 & (30 950) \\
\hline Primary care clinics & 4796 & 29 & 36 & 58 & 2.2 million & (314 300) & 38000 & $(5420)$ \\
\hline
\end{tabular}


Table 2. Community - Acquired (CA) MRSA Infections Originating in Sweden

\begin{tabular}{|c|c|c|c|c|c|c|c|c|c|c|c|c|c|c|c|}
\hline Years & Patient No. & Age/Se & & Origin/comments & SPA & PVL & $\mathrm{CC}$ & ISOXA $^{1}$ & ERY $^{2}$ & $\mathrm{CLI}^{3}$ & TOB $^{4}$ & RIF $^{5}$ & VAN $^{6}$ & FUS $^{7}$ & TRIM $^{8}$ \\
\hline \multirow[t]{9}{*}{2004} & 1 & 22 & $\mathrm{~F}$ & Wound leg. * & n.d. & pos & 1 & $\mathrm{R}$ & & S & S & & & S & \\
\hline & 2 & 59 & $\mathrm{~F}$ & Abscess & t 044 & neg & 80 & & & & & & & & \\
\hline & 3 & 88 & $\mathrm{~F}$ & Screened, skin lesions & t 044 & pos & 80 & $\mathrm{R}$ & & $S$ & S & $S$ & & & \\
\hline & 4 & $57 \mathrm{~N}$ & $\mathrm{M}$ & Abscess, abdomen & t 019 & pos & 30 & $\mathrm{R}$ & & $S$ & $\mathrm{~S}$ & $S$ & $\mathrm{~S}$ & $\mathrm{~S}$ & \\
\hline & 5 & $24 \mathrm{~N}$ & M & Wound, * digit & n.d. & pos & 1 & $\mathrm{R}$ & & $\mathrm{S}$ & $\mathrm{S}$ & $\mathrm{S}$ & & $\mathrm{S}$ & \\
\hline & 6 & $55 \mathrm{~N}$ & $\mathrm{M}$ & Wound, alcohol abuse & t 172 & neg & 59 & $\mathrm{R}$ & & $\mathrm{S}$ & S & $\mathrm{S}$ & & $\mathrm{S}$ & \\
\hline & 7 & 18 & M & Bite from police dog, drug abuse & $\mathrm{t} 172$ & neg & 59 & $\mathrm{R}$ & & $\mathrm{S}$ & $\mathrm{S}$ & $\mathrm{S}$ & $\mathrm{S}$ & $\mathrm{S}$ & \\
\hline & 8 & $68 \mathrm{~N}$ & M & Wound digit, diabetes & t 044 & pos & 80 & $\mathrm{R}$ & & $\mathrm{S}$ & $\mathrm{S}$ & $\mathrm{S}$ & $\mathrm{S}$ & $\mathrm{R}$ & \\
\hline & 9 & 86 & M & Wound leg, home for the elderly & $\mathrm{t} 008$ & neg & 8 & $\mathrm{R}$ & & $\mathrm{S}$ & $\mathrm{R}$ & $\mathrm{S}$ & $\mathrm{S}$ & $\mathrm{S}$ & \\
\hline \multirow[t]{11}{*}{2005} & 10 & 56 & M & Wounds, homeless, alcohol abuse & n.d. & n.d. & n.d. & - & - & - & - & - & - & - & \\
\hline & 11 & $29 \mathrm{~N}$ & M & Car accident, Stockholm & t 015 & neg & 45 & $\mathrm{R}$ & & $\mathrm{S}$ & $\mathrm{S}$ & $\mathrm{S}$ & & $\mathrm{R}$ & \\
\hline & 12 & $26 \mathrm{H}$ & $\mathrm{F}$ & Abscess since 2 months & t 044 & pos & 80 & $\mathrm{R}$ & & $\mathrm{S}$ & S & S & $\mathrm{S}$ & $\mathrm{R}$ & \\
\hline & 13 & 54 & $\mathrm{~F}$ & $\begin{array}{l}\text { Screened, homeless, } \\
\text { alcohol abuse, Stockholm }\end{array}$ & $\mathrm{t} 186$ & neg & 88 & & & & & & & & \\
\hline & 14 & 3 & M & Wound, digit since 3 months & t 008 & pos & 8 & $\mathrm{R}$ & & $\mathrm{S}$ & - & - & - & $\mathrm{S}$ & $\mathrm{S}$ \\
\hline & 15 & 18 & $\mathrm{~F}$ & Screened, relative to patient 14 & t 008 & pos & 8 & $\mathrm{R}$ & & $\mathrm{S}$ & $\mathrm{S}$ & $\mathrm{S}$ & $\mathrm{S}$ & $\mathrm{S}$ & $\mathrm{S}$ \\
\hline & 16 & $96 \mathrm{H}$ & $\mathrm{F}$ & Lesions leg, geriatric care & t 015 & neg & 45 & $\mathrm{R}$ & & $\mathrm{S}$ & $\mathrm{S}$ & $\mathrm{S}$ & $\mathrm{S}$ & $\mathrm{S}$ & $\mathrm{S}$ \\
\hline & 17 & 11 & & $\begin{array}{c}\text { Screened, before } \\
\text { surgery, Stockholm }\end{array}$ & t 015 & neg & 45 & & & & & & & & \\
\hline & 18 & 98 & $\mathrm{~F}$ & Urinary infection, geriatric care & t 1822 & neg & n.d. & $\mathrm{R}$ & & & & & & & $\mathrm{S}$ \\
\hline & 19 & $15 \mathrm{~N}$ & & Cystic fibrosis, Stockholm & t 002 & neg & 5 & & & & & & & & \\
\hline & 20 & 53 & $\mathrm{~F}$ & Tracheostomy, alcohol abuse & t 015 & n.d. & 45 & & & & & & & & \\
\hline \multirow[t]{2}{*}{2006} & 21 & 5 & M & Wound digit, immune suppression & n.d. & n.d. & n.d. & - & - & - & - & - & - & - & - \\
\hline & 22 & 63 & & $\begin{array}{c}\text { Tracheostomy, immune } \\
\text { suppression }\end{array}$ & t 1908 & neg & n.d. & $\mathrm{R}$ & & $\mathrm{S}$ & $\mathrm{S}$ & S & $\mathrm{S}$ & $\mathrm{S}$ & $\mathrm{S}$ \\
\hline
\end{tabular}

*Patients 1 and 5 visited the same Primary care clinic in Uppsala.

${ }^{1}$ Isoxapenicillin, ${ }^{2}$ Erthromycin, ${ }^{3}$ Clindamycin, ${ }^{4}$ Tetramycin, ${ }^{5}$ Rifampin, ${ }^{6}$ Vancomycin, ${ }^{7}$ Fusidic acid, ${ }^{8}$ Trimethoprim - Sulfamethoxazole .

Table 3. Health Care-Associated (HCA) MRSA Infections Originating in Sweden

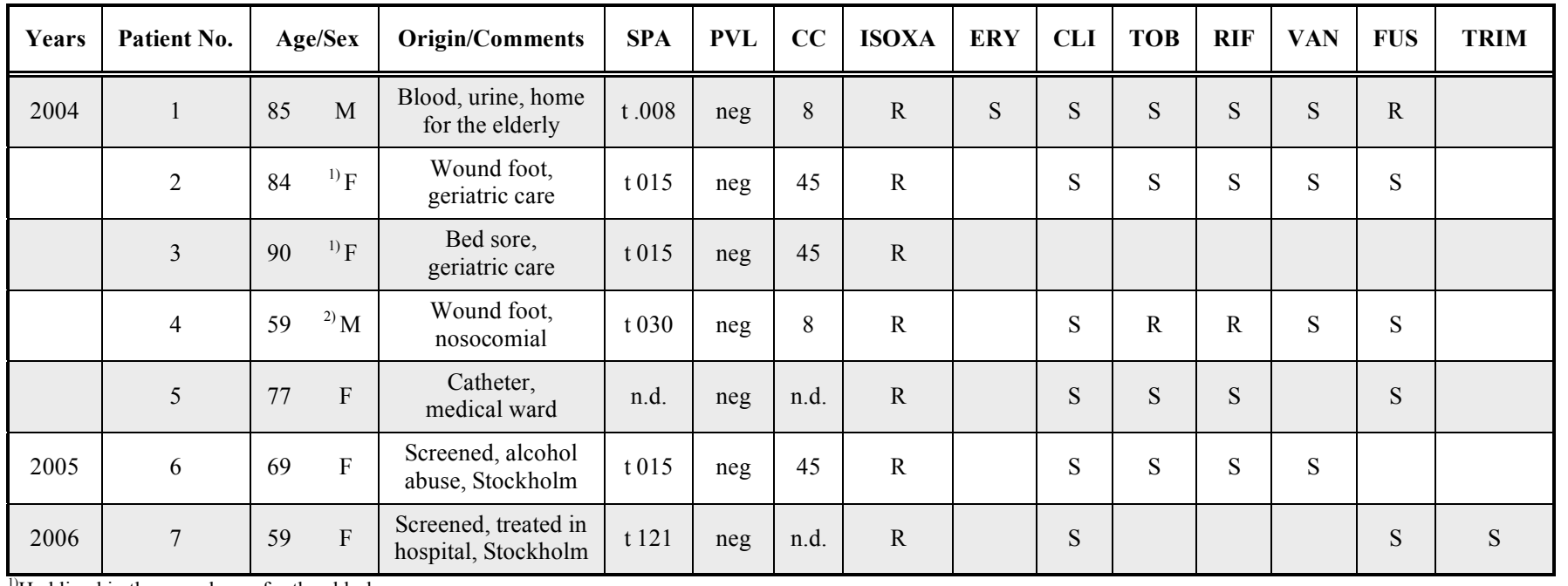

${ }^{1)}$ Had lived in the same home for the elderly.

${ }^{2}$ Same emergency ward as patients 2 and 3, Table 5 .

3), (iii) CA-MRSA infection acquired outside Sweden (Table 4) and (iv) HCA-MRSA infection acquired outside Sweden (Table 5).

\section{RESULTS}

During the 3-year surveillance study, samples were obtained from 7967 individuals; from whom 17634 isolates 
Table 4 Community-Acquired (CA) MRSA Infections Originating Outside of Sweden

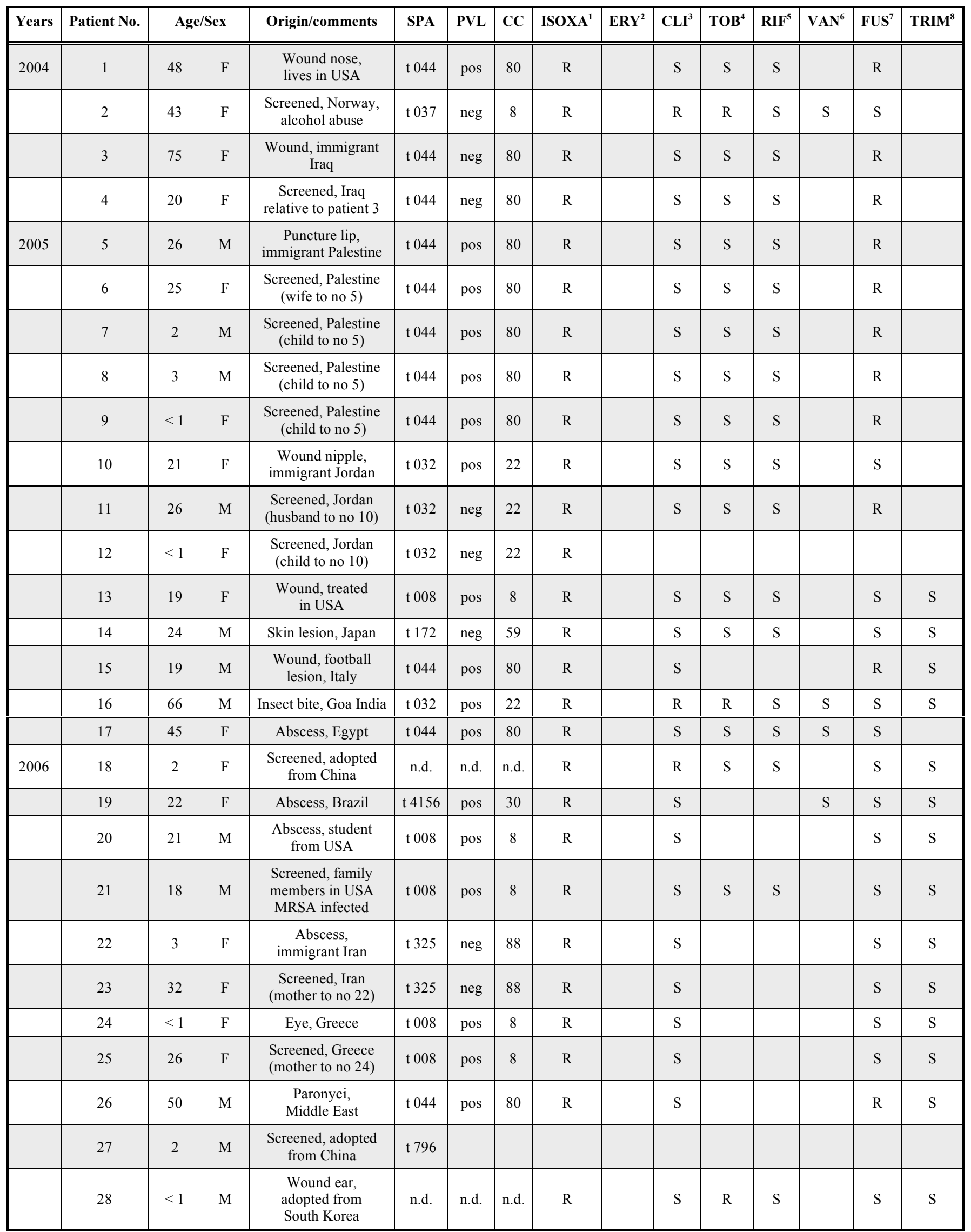




\begin{tabular}{|c|c|c|c|c|c|c|c|c|c|c|c|c|c|c|c|}
\hline Years & \begin{tabular}{c|} 
Patient No. \\
29
\end{tabular} & $<1$ & M & $\begin{array}{c}\text { Origin/comments } \\
\text { Screened before } \\
\text { surgery from Congo }\end{array}$ & $\begin{array}{l}\text { SPA } \\
\text { n.d. }\end{array}$ & $\begin{array}{l}\text { PVL } \\
\text { n.d. }\end{array}$ & $\begin{array}{l}\mathbf{C C} \\
\text { n.d. }\end{array}$ & $\operatorname{ISOXA}^{1}$ & ERY $^{2}$ & $\mathrm{CLI}^{3}$ & TOB $^{4}$ & RIF $^{5}$ & VAN $^{6}$ & FUS $^{7}$ & TRIM $^{8}$ \\
\hline & 30 & 29 & $\mathrm{~F}$ & $\begin{array}{l}\text { Wound knee, } \\
\text { Great Britain }\end{array}$ & t 008 & pos & 8 & $\mathrm{R}$ & & S & S & $\mathrm{S}$ & & S & $\mathrm{S}$ \\
\hline & 31 & 1 & M & $\begin{array}{l}\text { Screened, adopted } \\
\text { from Vietnam }\end{array}$ & t 909 & neg & n.d. & $\mathrm{R}$ & & $\mathrm{R}$ & & & & S & $\mathrm{S}$ \\
\hline & 32 & 22 & M & $\begin{array}{l}\text { Abscess, student } \\
\text { from USA }\end{array}$ & t 008 & pos & 8 & $\mathrm{R}$ & & S & S & S & & S & S \\
\hline & 33 & 47 & M & $\begin{array}{l}\text { Wound, immigrant } \\
\text { Bangladesh }\end{array}$ & t 304 & neg & n.d. & $\mathrm{R}$ & & S & S & S & & S & S \\
\hline & 34 & 23 & F & $\begin{array}{c}\text { Screened } \\
\text { (wife to no 33) }\end{array}$ & t 304 & neg & n.d. & $\mathrm{R}$ & & $\mathrm{S}$ & S & $\mathrm{S}$ & & S & $\mathrm{S}$ \\
\hline
\end{tabular}

${ }^{1}$ Isoxapenicillin, ${ }^{2}$ Erythromycin, ${ }^{3}$ Clindamycin, ${ }^{4}$ Tetramycin, ${ }^{5}$ Rifampin, ${ }^{6}$ Vancomycin, ${ }^{7}$ Fusidic acid, ${ }^{8}$ Trimethoprim - Sulfamethoxazole.

were collected; of these 82 (58 CA and $24 \mathrm{HCA}$ ) were colonised or infected with MRSA. Twenty-nine persons (35\%) were domestically infected (22 CA and 7 HCA), of whom 6 were colonised with MRSA, which was discovered through active screening (Tables 2 and $\mathbf{3}$ ). Most domestic cases had a documented co-existing condition or risk factor, such as alcohol or injecting drug abuse, cystic fibrosis, tracheotomy or immune suppression. High age was observed in seven domestic patients (mean age of 89.6 years).

In 53 cases (65\%) MRSA were acquired abroad (36 CA and $17 \mathrm{HCA}$ ), of whom 30 were infected and 23 colonised with MRSA (Tables 4 and 5). Nosocomial infection was documented in one patient treated at the same emergency ward as two patients who originated and were treated in Turkey (Table 5). During the surveillance a decrease of MRSA infections originating in Sweden was observed from 14 isolates in 2004 to 12 in 2005 and 3 in 2006, whereas isolates originating from patients infected abroad increased from 13 isolates in 2004 to 17 in 2005 and 23 in 2006.

Clonal complex. Sixty-five isolates could be assigned to nine clonal complexes based on the similarity between sequence types in different loci $(\mathrm{CC} 1,-5-8,-22,-30,-45$, $59,-80$ and -88). All clonal complexes were found in community-acquired isolates and 5 only as $\mathrm{CA}$ isolates (CC88, CC80, CC59, CC22 and CC1). The most frequent represented clone (CC8) was found in $21(32 \%)$ isolates: 5 domestic ( $3 \mathrm{CA}$ and $2 \mathrm{HCA}$ ) and 16 isolates acquired abroad ( 8 HCA and $8 \mathrm{CA}$ ) (Tables 4 and 5). The CC8 represents different clonal complexes and by PFGE four international clusters were identified: Fra A, Fra B, UK E1 and USA300like patterns. Three of six isolates from the USA had a USA300 PFGE pattern. Using spa typing, t008 was found in 13 isolates while t030 and t037 were found in 4 isolates each.

The next most frequent clone, CC80, was found in 15 CA-isolates (23\%), 4 domestic and 11 imported abroad, and identical to the reference strain DK E97-1 (spa type t044). The same PFGE pattern (DK E97-1) was found in $80 \%$ of the isolates and in the remaining three isolates subtypes to this PFGE pattern. Resistance to fusidic acid was found in 11 of 12 investigated CC 80 isolates.

Other clones, only discovered in CA-isolates, were $\mathrm{CC} 22$ (UK E15-like), CC59 and CC88. The CC22 clone originally described in Europe, was found in four imported isolates (Jordan and India, spa type t032), which is frequently associated with this clone. The CC59 clone (spa type t172) was found in two domestic isolates and in one isolate from Japan, while CC88 was discovered in one domestic (spa type t186) and two isolates from Iran (spa type t325).

The CC5 clone (Bel EC-3a like) was discovered in five HCA isolates originating abroad, (spa types t002, t003 and t067) and in one CA domestic carrier (spa type t002) (Tables 2 and 5). The CC30 clone (United Kingdom EMRSA-16) was found in one HCA isolates originating from Iran (spa type t019) and one CA isolate from Brazil (spa type t4156).

Two clones, CC45 (Berlin-1V like clone) and CC1, were only found in domestic isolates (Tables 2 and 3). The CC1 clone was found in two young persons, with the only link being that they had visited the same primary care clinic on different occasions in 2004 (Table 2).

Resistance pattern. Resistance to antibiotics other than $\beta$-lactams was found in $25 \%$ of the MRSA isolates originating in Sweden and in $60 \%$ of the MRSA isolates originating abroad. Of the HCA isolates originating abroad, $80 \%$ were resistant to more than $\beta$-lactams whereas the corresponding figure for domestic HCA isolates was only $16 \%$.

None of the HCA-MRSA isolates carried the virulence determinant PVL gene, whereas $52 \%$ of the CA-MRSA isolates harboured the gene.

The resistance pattern was not known in 5 MRSA isolates originating in Stockholm.

Cost of MRSA isolates. The cost of identifying 24 HCA-MRSA infections from 12838 isolates was 5.2 million 
Table 5. Health Care-Associated (HCA) MRSA Infections Originating Outside of Sweden

\begin{tabular}{|c|c|c|c|c|c|c|c|c|c|c|c|c|c|c|c|}
\hline Years & Patient No. & & Sex & Origin/Comments & SPA & PVL & $\mathbf{C C}$ & ISOXA & ERY & CLI & TOB & RIF & VAN & FUS & TRIM \\
\hline \multirow[t]{9}{*}{2004} & 1 & 69 & $\mathrm{~F}$ & Screened, treated in USA & $\mathrm{t} .030$ & neg & 8 & $\mathrm{R}$ & & S & $\mathrm{R}$ & S & $\mathrm{S}$ & & \\
\hline & 2 & 27 & M & $\begin{array}{l}\text { Lesions, accident } \\
\text { and origin Turkey }\end{array}$ & $\mathrm{t} 030$ & neg & 8 & $\mathrm{R}$ & & $\mathrm{S}$ & $\mathrm{R}$ & $\mathrm{R}$ & $\mathrm{S}$ & $\mathrm{S}$ & \\
\hline & 3 & 73 & $\mathrm{~F}$ & $\begin{array}{l}\text { Lesions, accident and } \\
\text { origin Turkey }\end{array}$ & t 030 & neg & 8 & $\mathrm{R}$ & & $\mathrm{S}$ & $\mathrm{R}$ & $\mathrm{R}$ & $\mathrm{S}$ & $\mathrm{S}$ & \\
\hline & 4 & 32 & M & Abscess, from USA & t 008 & neg & 8 & $\mathrm{R}$ & $\mathrm{R}$ & $\mathrm{S}$ & $\mathrm{S}$ & $\mathrm{S}$ & $\mathrm{S}$ & $\mathrm{S}$ & \\
\hline & 5 & 28 & M & Screened, treated in USA & t 002 & neg & 5 & $\mathrm{R}$ & & $\mathrm{R}$ & $\mathrm{R}$ & S & S & S & \\
\hline & 6 & 37 & $\mathrm{M}$ & Wounds, immigrant Iraq & t 037 & neg & 8 & $\mathrm{R}$ & $\mathrm{R}$ & $\mathrm{R}$ & $\mathrm{R}$ & $\mathrm{S}$ & S & $\mathrm{S}$ & \\
\hline & 7 & 60 & $\mathrm{~F}$ & $\begin{array}{l}\text { Wounds, accident } \\
\text { Scotland }\end{array}$ & n.d. & n.d. & n.d. & & & & & & & & \\
\hline & 8 & 43 & M & Screened, immigrant Iran & t 019 & neg & 30 & $\mathrm{R}$ & & $\mathrm{R}$ & $\mathrm{R}$ & $\mathrm{S}$ & $\mathrm{S}$ & $\mathrm{S}$ & \\
\hline & 9 & 19 & $\mathrm{~F}$ & Screened, traveled Egypt & unique & neg & n.d. & $\mathrm{R}$ & & $\mathrm{S}$ & $\mathrm{S}$ & $\mathrm{S}$ & S & & \\
\hline \multirow[t]{4}{*}{2005} & 10 & 34 & M & Skin lesion, Thailand & t 008 & neg & 8 & $\mathrm{R}$ & & $\mathrm{R}$ & $\mathrm{R}$ & $\mathrm{S}$ & $\mathrm{S}$ & $\mathrm{S}$ & \\
\hline & 11 & 68 & $\mathrm{~F}$ & $\begin{array}{c}\text { Screened, } \\
\text { immigrant Syria }\end{array}$ & n.d. & n.d. & n.d. & $\mathrm{R}$ & & $\mathrm{S}$ & $\mathrm{S}$ & & & $\mathrm{S}$ & \\
\hline & 12 & 46 & M & $\begin{array}{l}\text { Tracheostomy, } \\
\text { immigrant Bangladesh }\end{array}$ & t 037 & neg & 8 & $\mathrm{R}$ & & $\mathrm{R}$ & $\mathrm{R}$ & $\mathrm{S}$ & & $\mathrm{S}$ & $\mathrm{R}$ \\
\hline & 13 & 21 & $\mathrm{~F}$ & $\begin{array}{l}\text { Screened, treated } \\
\text { in Spain }\end{array}$ & t 002 & neg & 5 & $\mathrm{R}$ & & $\mathrm{R}$ & $\mathrm{R}$ & $\mathrm{S}$ & $\mathrm{S}$ & $\mathrm{S}$ & $\mathrm{S}$ \\
\hline \multirow[t]{4}{*}{2006} & 14 & 66 & $\mathrm{M}$ & $\begin{array}{l}\text { Drenage, surgery } \\
\text { in Spain }\end{array}$ & t 067 & neg & 5 & $\mathrm{R}$ & $\mathrm{R}$ & $\mathrm{S}$ & $\mathrm{R}$ & $\mathrm{S}$ & & $\mathrm{S}$ & $\mathrm{S}$ \\
\hline & 15 & 42 & $\mathrm{M}$ & $\begin{array}{l}\text { Avscess, treated } \\
\text { in Germany }\end{array}$ & t 003 & neg & 5 & $\mathrm{R}$ & & $\mathrm{R}$ & $\mathrm{R}$ & $\mathrm{S}$ & $\mathrm{S}$ & $\mathrm{S}$ & $\mathrm{S}$ \\
\hline & 16 & 23 & $\mathrm{M}$ & $\begin{array}{l}\text { Screened, treated } \\
\text { in Japan }\end{array}$ & t 334 & neg & 5 & $\mathrm{R}$ & & I & $\mathrm{R}$ & $\mathrm{S}$ & & $\mathrm{S}$ & $\mathrm{S}$ \\
\hline & 17 & 78 & M & $\begin{array}{l}\text { Screened, immigrant } \\
\text { Iran }\end{array}$ & t 037 & neg & 8 & $\mathrm{R}$ & & & & & & & \\
\hline
\end{tabular}

SEK (or 742900 USD), which is equivalent to 216700 SEK (30 950 USD) per identified patient (Table 1). The cost for each of the 58 CA infections was 38000 SEK (5 420 USD). These figures show that the cost for only bacterial isolation was 7.4 million SEK (or 1.05 million USD). Of the 82 MRSA-infected persons, 30 were carriers detected in contact tracing and screening. MRSA was not considered the cause of the gravidity of the illness in any of the cases.

\section{DISCUSSION}

MRSA infections have mostly been associated with infections in hospitals but more recently an increasing number of CA-MRSA strains have been described $[2,5]$. In many countries CA infections have become epidemic, differing from nosocomial MRSA infections in several characteristics, including virulence and antibiotic susceptibility factors $[8,11,12]$. Usually, CA-MRSA causes skin and soft tissue infections in otherwise healthy individuals. However, reports of serious infections and necrotising pneumonia of CA-MRSA in children and adolescents without predisposing factors have raised concern about the severity of the infection [20,21]. It has been revealed that certain strains are able to cause clonal epidemics, whereas others have a more incidental occasion [22-24]. Major clonal complexes are spread over the world, with growing evidence of a rapid evolution of MRSA [25, 26]. The prevalence of CA-MRSA seems to be lower in Europe than in the USA but recent reports indicate that CAMRSA infections are increasing in Europe as well. In contrast to the situation in the USA, where one clone (the USA300) dominates, there are a number of clones circulating in Europe. The epidemiology of clonal complexes indicates that these clones can be classified into at least nine clonal types, with five representing common global complexes $[25,26]$.

Thus far, Sweden has been a low-epidemic area concerning both HCA-MRSA and CA-MRSA infections. However, reports of an increasing incidence of CA-MRSA infections in several countries and outbreaks of MRSA in Stockholm in 2002 and in Gothenburg in 1999 [27] have elevated the concern about this recognised threat of MRSA.

However, despite that nearly 18000 isolates from 7967 persons have been obtained during 3 years of surveillance in Uppsala County, only 82 cases, of colonised or infected MRSA were identified. The cost of bacterial isolation of MRSA (other costs not included) was more than 7.2 million SEK (>1million USD), which translates to 90244 SEK (13 000 USD) per identified individual (Table 1). None of the patients had a serious illness related to MRSA infection. 
A majority of both CA-and HCA-MRSA isolates originated abroad (62 and $71 \%$, respectively). It might be questioned if some of the foreign born family members had acquired the MRSA infection outside or inside Sweden but as the infection originated outside Sweden it was classified as originating abroad. It is likely that family members discovered in contact tracing had been carriers for a long time. Of 53 MRSA infections originating abroad, $83 \%$ were derived outside the borders of Europe. Resistance to antibiotics other than $\beta$-lactams was $60 \%$ in isolates from abroad as compared with only $25 \%$ of domestic isolates. Most domestic infected patients had a risk factor that could be identified. These risk factors were chronic disease, immune suppression, alcohol or drug abuse and high age.

In this study widely disseminated international clones dominated. The most frequent clone, CC8, was found in 21 isolates, demonstrating different strains with pronounced genetic diversity and a wide geographic distribution. A majority of the CC8 isolates (76\%), equally distributed between CA-and HCA-MRSA infections, originated outside Sweden. The CC8 clone is related to the widespread clone USA300, (sequence type 8) which has been reported to spread rapidly in the community, largely by direct person-toperson contact but rarely causing serious infections in healthy individuals $[28,29]$. However, serious and unusual infections have been described $[9,24]$. Furthermore, the USA300 strains are on the rise in Europe [29]. Six of the CC8 isolates were acquired in the USA and three had a PFGE pattern similar to the USA300 strain of MRSA.

The next most common clone, CC80 (23\%), was only found in CA isolates, with the majority (73\%) of infections having their origin outside Sweden. A pronounced homogeneity of the CC80 isolates was found, in which $80 \%$ showed the same PFGE-pattern (DK E97-1); the remaining isolates were subtypes to this PFGE pattern. All of the CC80 isolates demonstrated spa type t044 and were resistant to fusidic acid.

Reports of the epidemiology of CA-MRSA isolates in Europe have shown that CC 80 was a frequent source of transmission to an increasing number of countries. The CC80 has been found to be one of the most common CAMRSA isolates in Denmark and was recently discovered in HCA-isolates [14]. The CC80 caused invasive infections among young healthy individuals and had an ability to spread among family and household members. We found no spread of CC80 from domestic cases, whereas there was an extensive dissemination among family members from isolates of non-European origin. The PVL gene was expressed in all CC80 isolates. Resistance to fusidic acid, which is characteristic of CC 80 was discovered in $92 \%$ of the investigated isolates. In a Swedish study from Örebro County, CC 80 and CC45 represented the predominant clonal complexes [15].

Pandemic MRSA clones, CC22 (EMRSA-15) and CC30 (EMRSA-16), the dominating causes of MRSA in the United Kingdom and several other countries, were discovered only in isolates originating outside Europe

Clonal complexes, only discovered in domestic isolates were $\mathrm{CC} 45$ and $\mathrm{CC} 1$ and no resistance to other antibiotics than $\beta$-lactams was found. CC45 was found both in CA-and
HCA isolates. High age was noted in three cases (mean age 90 years). Other factors observed were alcohol abuse and a link to Stockholm. Two of the high-age patients had visited the same geriatric long-term facility (Table 3). However, an association could not be demonstrated and it has been indicated that there is only a limited emergence of MRSA strains among geriatric patients [30].

The $\mathrm{CCl}$ isolates were obtained from two young domestic cases with the only known connection that they had visited the same primary health clinic on different occasions during 2004 and lived in the same area in Uppsala.

Nosocomial infection was only discovered in one patient treated on the same emergency ward as two patients originating from Turkey and where the same resistance pattern and spa type were found (CC8, t030). Despite extensive screening of health care personnel and patients in hospital and nursing homes in association with MRSA infections, no further spread was revealed. This finding indicates that with effective infection control measures, perfunctory screening of nursing staff which sometimes can be experienced as integrity infringement might not be required.

Recent travel or familities to Asia and the Middle East was highly overrepresented indicating that MRSA isolates imported outside Europe are the main source for CA-MRSA strains. During the study, there was a decrease in domestic isolates, whereas the MRSA infections originating outside Sweden increased. After the study period 2006 and until 2011, the MRSA infections have remained at a low level, with between 30 and 40 cases yearly. Approximately $50 \%$ of the MRSA cases originating from abroad and $50 \%$ being carriers discovered in contact tracing.

\section{CONCLUSIONS}

Sweden is still a low prevalence country. No evidence of spread or increase of MRSA infections in community or hospital settings was found. The majority of MRSA infections originated outside of Sweden. Travellers from or family relatives in the Middle East or Asia were highly overrepresented. In contrast, risk factors or underlying predisposing diseases accounted for those patients infected in Sweden.

To reduce costs selected screening of high-risk groups should be implemented and special attention paid to potential risk factors.

\section{REFERENCES}

[1] Mark CE. Genome of an epidemic community-acquired MRSA. Lancet 2005; 367: 705-6

[2] Corporate author. European Antimicrobial Resistance Surveillance System. 2006. EARSS annual report 2005; http://www.rivm.nl/ earss/

[3] Biedenback D, Moet G, Rones R. Occurrence and antimicrobial resistance pattern comparisons among bloodstream infection isolates from the SENTRY Antimicrobial Surveillance Program (1997-2002). Diagn Microbiol Infect Dis. 2004; 50: 5969.

[4] Adam D, Kennedy, Frank R. Epidemiology and virulence of Community-Associated MRSA. Clin Microbiol Newslett 2009; 31: 153-60.

[5] King MD, Humphrey BJ, Wang YF, Kourbatova EV, Ray SM, Blumberg HM. Emergence of community-acquired methicillinresistant Staphylococcus aureus USA 300 clone as the predominant cause of skin and soft-tissue infections. Ann Intern Med 2006; 144(5): 309-17. 
[6] Corporate author. Centers for Disease Control and Prevention. Four pediatric deaths from community-acquired methicillin-resistant Staphylococcus aureus-Minnesota and North Dakota, 1997-1999. JAMA 1999; 282: 1123-5.

[7] Diep BA, Sensabaugh GF, Somboona NS, Carleton HA, PendreauRemigton F. Widespread skin and soft-tissue infections due to two methicillin-resistant Staphylococcus aureus strains harbouring the genes for Panton-Valentine leukocidin. J Clin Microbiol 2004; 42: 2080-4.

[8] Tristan A, Tristan F, Durand G, et al. Virulence determinants in community and hospital methicillin-resistant Staphylococcus aureus. J Hospital Infect 2007; 65: 105-9.

[9] Miller LG, Perdreau-Remington F, Rieg G, et al. Necrotizing Fasciitis caused by community-associated methicillin-resistant Staphylococcus aureus in Los Angeles. N Engl J Med 2005; 352: 1445-53.

[10] Oliveira DC, Tomasz A, de Lencastre H. Secrets of success of human pathogen: molecular evolution of pandemic clones of methicillin resistant Staphylococcus aureus. Lancet Infect Dis 2002; 2: 180-9.

[11] Cristomo MI, West H, Tomasz A, Chung M, Oliveira DC, de Lencastre $H$. The evolution of methicillin resistance in Staphylococcus aureus: similarity of genetic backgrounds in historically early methicillin-susceptible and -resistant isolates and contemporary epidemic clones. Proc. Natl Acad Sci USA 2001; 98 : 9865-70.

[12] Baba T, Takeuchi F, Kuroda M, et al. Genome and virulence determinants of high virulence community-acquired MRSA. Lancet 2002; 359: 1819-27.

[13] Bonnstetter KK, Wolter DJ, Tenover, McDougal LK, Goering RV. Apid multilplex PCR assay for identification of USA300 Community- Associated Methicillin-Resistant Staphylococcus aureus Isolates. J Clin Microbiol 2007; 45: 141-6.

[14] Larsen AR, Böcher S, Stegger M, Goering R, Pallesen LV, Skov R. Epidemiology of European Community-associated MethicillinResistant Staphylococcus aureus Clonal Complex 80 Type IV Strains isolated in Denmark from 1993 to 2004. Am Soci Microbiol 2008; 46: 0095-1128.

[15] Berglund C, Mölling P, Sjöberg L, Söderquist B. Multilocus Sequence Typing of Methicillin-Resistant Staphylococcus aureus from an area of Low Endemicity by Real-Time PCR. J Clin Microbiol 2005; 43: 4448-54.

[16] Murchan S, Kaufmann ME, Deplano A, et al. Harmonization of pulsed-field gel electrophoresis protocols for epidemiological typing of strains of methicillin-resistant Staphylococcus aureus: a single approach by consensus in 10European laboratories and its application for tracing the spread of related strains. J Clin Microbiol 2003; 41: 1574-85.
[17] Shopsin B, Gomez M, Montgomery SO, et al. Evaluation of protein A gene polymorphic region DNA sequencing for typing of Staphylococcus aureus strain. J Clin Microbiol 1999; 37: 3556-63.

[18] Enright MC, Day NP, Davie CE, Peacock SJ, Spratt BG Multilocus sequence typing for characterization of methicillinsusceptible clones of Staphylococcus aureus. J Clin Microbiol 2000; 38: 1008-15.

[19] Etienne J. Panton-Valentine leukocidin: a marker of severity for Staphylococcus aureus infection? Clin Infect Dis 2005; 41: 591-3.

[20] Francis JS, Doherty MC, Lopatin U, et al. Severe community-onset pneumonia in healthy adults caused by methicillin-resistant Staphylococcus aureus carrying the Panton-Valentine leukocidin genes. Clin infect Dis 2005; 40: 100-7.

[21] Gonzalez BE, Martinez-Aguilar G, Hulten KG, et al. Severe staphylococcal sepsis in adolescents in the era of communityacquired methicillin-resistant Staphylococcus aureus. Pediatrics 2005; 115: 642-8.

[22] Centers for Disease Control and Prevention, Public health dispatch: outbreaks of community-associated methicillin-resistant Staphylococcus aureus skin infection- Los Angeles County, California 2002-2003. JAMA 2003; 289:1377.

[23] Adem PV, Montgomery JP, Husain AN, et al. Staphylococcus aureus sepsis and the Waterhous-Friderichsen syndrome in children. N Engl J Med 2005; 353: 1245-51.

[24] Bicchini CE, Hulten KG, Mason EO, Gonzalez BE, Hammaerman WA, Kaplan SL. Panton-Valentine leukocidin genes are associated with enhanced inflammatory response and local disease in acute hematogenous Staphylococcus aureus osteomyelitis in children. Pediatrics 2006; 117: 433- 40.

[25] Robinson DA, Enright MC. Evolutionary models of the emergence of methicillin-resistant Staphylococcus aureus. Antimicrob Agents Chemother 2003; 47: 3926-34.

[26] Enright MC, Robinson DA, Randle G, Feil EJ, Grundmann H, Spratt BG. The evolutionary history of methicillin-resistant Staphylococcus aureus (MRSA). Proc Natl Acad Sci USA 2002; 99: 7687-92.

[27] Seeberg S, Larsson L, Welinder-Olsson C, et al. How an outbreak of MRSA in Gothenburg was eliminated: by strict hygienic routines and massive control-culture program. Lakartidningen 2002; 99: 3198-204. (In Swedish) (Medline)

[28] Diep BA, Gill SR, Chang RF, et al. Complete genome sequence of USA300, an epidemic clone of community-acquired methicillinresistant Staphylococcus aureus. Lancet 2006; 367: 737-9.

[29] Barlett JG. Methicillin-resistant Staphylococcus aureus infections. Top HIV Med 2008; 16(5): 151-5.

[30] Hoefnagels-Schuermans A, Borremans A, Peetermans W, Van Lierde S, Reybrouck G, Van Eldere J. Origin and transmission of methicillin-resistant Staphylococcus aureus in an endemic situation: differences between geriatric and intensive-care patients. J Hosp Inf 1997; 36: 209-22.

(C) Christenson et al.; Licensee Bentham Open.

This is an open access article licensed under the terms of the Creative Commons Attribution Non-Commercial License (http://creativecommons.org/licenses/ by-nc/3.0/) which permits unrestricted, non-commercial use, distribution and reproduction in any medium, provided the work is properly cited. 